\title{
Structure of Posttraumatic Stress Disorder Symptoms in Pain and Pain-Free Patients Scheduled for Major Surgery
}

\author{
Gabrielle M. Pagé, ${ }^{\star}$ Valery Kleiman, ${ }^{*}$ Gordon J. G. Asmundson, ${ }^{\dagger}$ and Joel Katz ${ }^{\star \ddagger \S}$ \\ * Department of Psychology, Faculty of Health, York University, Toronto, Ontario, Canada. \\ †Department of Psychology, University of Regina, Regina, Saskatchewan, Canada. \\ $\ddagger$ Department of Anesthesia and Pain Management, Toronto General Hospital, Toronto, Ontario, Canada, and Mount \\ Sinai Hospital, Toronto, Ontario, Canada. \\ ${ }^{\S}$ Department of Anesthesia, University of Toronto, Toronto, Ontario, Canada.
}

\begin{abstract}
Factor-analytic studies of the structure of posttraumatic stress disorder (PTSD) symptoms have yielded inconsistent results. One of the reasons for the inconsistency may be that PTSD is highly comorbid with other disorders; the observed factor structure might depend on the particular comorbid disorder. One such disorder is chronic pain. The goal of the present study was to investigate whether PTSD symptom structure differs between pain and pain-free patients scheduled to undergo major surgery. Four hundred and forty-seven patients who were approached 7 to 10 days prior to scheduled surgery completed the PTSD Checklist-Civilian (PCL-C) Version and the Current Pain and Pain History Questionnaire; the latter was used to divide patients into pain $(N=175)$ and pain-free $(N=272)$ groups. Results showed that in pain-free patients, PTSD symptoms were best expressed as 2 symptom clusters (re-experiencing/avoidance; emotional numbing/hyperarousal) accounting for $52.4 \%$ of the variance. In pain patients, PTSD symptoms were best expressed as a single symptom cluster accounting for $51.1 \%$ of the variance. These results suggest different interrelationships among PTSD symptoms in these 2 populations. Results reflect the need for (1) controlling for pain in studies looking at PTSD-symptom expression and (2) further research on PTSD-symptom expression in pain populations.

Perspective: These results may have important implications for research on the comorbidity between PTSD and chronic pain, as well as for treatment of PTSD symptoms in patients presenting with pain problems.
\end{abstract}

Key words: PTSD, pain, factor analysis, symptom structure, comorbidity.

$\mathrm{R}$ ecent studies have reported high rates of comorbidity between Posttraumatic Stress Disorder (PTSD) and pain in both veterans (50-80\%) and civilians (20-30\%). ${ }^{3,33}$ According to the DSM-IV-TR, ${ }^{1}$ PTSD is classified as an anxiety disorder that develops following the occurrence of a traumatic event. Additional diagnostic criteria include the presence of the following 3 symptom categories for a period of at least 1 month: re-experiencing, avoidance and emotional numbing, and hyperarousal. ${ }^{1}$ This working definition of PTSD, however, has some drawbacks (eg, lack of specificity, difficulty explaining high comorbidity rates with other disorders not associated with trauma, lack of empirical support for 3 symptom categories). ${ }^{9}$

To explain this comorbidity, Sharp and Harvey ${ }^{40}$ have put forward a mutual maintenance model in which various aspects of chronic pain and PTSD play a role in the maintenance of PTSD and pain symptoms, respectively. These include attentional biases, anxiety sensitivity (fear of anxiety-related sensations due to the belief that they might have harmful consequences ${ }^{38}$ ), reminders of the trauma, avoidance, depression and anxiety, and cognitive demand from symptoms. ${ }^{40}$ Alternatively, Asmundson et $\mathrm{al}^{3}$ have proposed a shared vulnerability model in which common vulnerability factors increase the risk of developing both conditions. However, etiological and maintenance mechanisms responsible for the observed comorbidity are still poorly understood. 
It is possible that the lack of understanding of comorbid PTSD and pain is related to the undifferentiated way PTSD is measured across populations. One study assessed the factor-analytic structure of PTSD symptoms in individuals (peacekeepers) with and without pain. Confirmatory factor analysis showed the same 2- and 4-factor solutions in both groups, with some significant differences in factor loadings of hyperarousal and re-experiencing items. ${ }^{5}$

There are several reasons why one might expect differences in PTSD symptom structure between pain and painfree patients. First, the heterogeneity of symptom expression in PTSD gives rise to a single diagnosis that can comprise multiple, different symptom combinations. ${ }^{10}$ For example, an individual can meet criteria for PTSD without experiencing either avoidance or emotional numbing symptoms. However, it is likely that these 2 classes of symptoms arise from different etiological mechanisms. Individuals consciously engage in avoidance behaviors in attempts to escape from a particular stressor. On the other hand, emotional numbing is a self-protective response to increased and prolonged arousal that limits the individual from further exposure to these stressors ${ }^{21}$. Thus, the same diagnosis can apply to a disorder that differs mechanistically and experientially depending on the particular combination of symptoms.

Second, emotional numbing, which is unique to PTSD among the anxiety disorders, ${ }^{21}$ plays a distinctive role among pain patients with PTSD symptoms. For example, emotional numbing interacts with pain intensity in predicting quality of life among patients with chronic pain ${ }^{14}$ and, in contrast to avoidance symptoms, predicts pain disability 6 and 12 months after thoracic surgery ${ }^{27}$.

The goal of the current factor-analytic study is to investigate whether the interrelationships among PTSD symptoms differ between pain and pain-free patients scheduled to undergo major surgery. Examining PTSDsymptom structure in this population is advantageous as it offers the possibility of studying the full spectrum of PTSD symptom expression. This approach is consistent with findings suggesting that PTSD is best conceptualized along a continuum. ${ }^{11}$ If results show that the factor structure is different in pain patients compared to pain-free patients, future research on PTSD would need to control for pain when studying PTSD; studies on the comorbidity of PTSD and pain should use a different approach to diagnose PTSD in pain patients. These results would also be important for clinicians if PTSD symptom expression differs in patients who also present with pain symptoms.

\section{Methods}

\section{Participants}

Data from 447 patients (male $=177$ ) were collected 7 to 10 days prior to major surgery (abdominal [71.5\%]; thoracic [17.3\%]; other [11.2\%]). Patients were recruited to participate in a study examining biopsychological factors associated with acute and long-term postoperative pain. Patients were between the ages of 18 and 60 years (mean $=45.67 ; \mathrm{SD}=10.3$ years). Sixty-one percent of patients $(\mathrm{N}=272)$ reported no ongoing pain problems and not currently experiencing pain. Thirty-nine percent of patients $(\mathrm{N}=175)$ reported ongoing pain problems with $50.1 \%$ of these patients reporting pain at the time of the interview. Details of the pain experienced by patients in the pain group are described in Table 1. Fourteen percent of the sample $(N=65)$, including 38 pain patients, had a total score on the PTSD Checklist-Civilian Version (PCL-C) equal to or greater than 44 (a score of 44 or higher on the PCL-C indicates PTSD symptom severity that is within the clinical range) ${ }^{8}$

\section{Measures}

\section{PTSD Checklist - Civilian Version (PCL- ${ }^{46}$ )}

The PCL-C is a 17-item self-report measure that assesses PTSD symptoms as described in the diagnostic criteria $B, C$, and D of the DSM-IV-TR. ${ }^{1}$ Participants answer each item on a scale from 1 (not at all) to 5 (extremely). Total score ranges from 17 to 85 . Symptom-cluster scores can be obtained by summing items belonging to that cluster: items 1 to 5 for the re-experiencing cluster; items 6 to 12 for the avoidance (items 6 and 7)/emotional numbing (items 8 to 12) cluster; and items 13 to 17 for the hyperarousal cluster. ${ }^{4}$ The PCL-C has good sensitivity and specificity for generating PTSD diagnosis. ${ }^{22,47}$ Correlation among items of the PCL-C is high $(r=.93)$, and the PCL-Chas good internal consistency at both the global $(\alpha=.94)$ and subscale levels $(\alpha=.85-.87){ }^{39}$ Test-retest reliability coefficient was equal to .68 at a 2-week interval. ${ }^{39}$

Table 1. Pain Information from the Current Pain and Pain History Questionnaire for Pain Patients

\begin{tabular}{|c|c|}
\hline $\begin{array}{l}\text { Have you ever had a pain } \\
\text { problem that lasted for more } \\
\text { than } 1 \text { month? }\end{array}$ & Yes $=53 \quad$ No $=122$ \\
\hline $\begin{array}{l}\text { If yes, how long did it last } \\
\text { (in months)? }\end{array}$ & Mean $=33.42 \quad S D=52.62$ \\
\hline $\begin{array}{l}\text { Do you have any ongoing pain } \\
\text { problems? }\end{array}$ & Yes $=175 \quad$ No $=0$ \\
\hline $\begin{array}{l}\text { If yes, how long have you had } \\
\text { pain for (in months)? }\end{array}$ & Mean $=67.92 \quad S D=94.53$ \\
\hline $\begin{array}{l}\text { On the days that you feel pain, } \\
\text { what is the average intensity } \\
\text { of your pain on a scale from } \\
1 \text { to } 10 \text { ? }\end{array}$ & Mean $=5.69 \quad S D=2.48$ \\
\hline Are you currently feeling pain? & Yes $=89 \quad \mathrm{No}=85$ \\
\hline $\begin{array}{l}\text { If yes, what is the intensity of } \\
\text { your pain on the scale from } \\
1 \text { to } 10 \text { ? }\end{array}$ & Mean $=4.07 \quad S D=2.26$ \\
\hline $\begin{array}{l}\text { If yes, does pain interfere with } \\
\text { your life ( } 1 \text { to } 4) \text { ? }\end{array}$ & Mean $=2.74 \quad S D=1.00$ \\
\hline $\begin{array}{l}\text { Are you currently taking pain } \\
\text { medication? }\end{array}$ & Yes $=87 \quad$ No $=85$ \\
\hline $\begin{array}{l}\text { *If yes, what type of pain } \\
\text { medication? }\end{array}$ & $\begin{array}{l}\text { Acetaminophen }=56 \\
\text { Nsaids }=12 \\
\text { Opioids }=27 \\
\text { Others }=4\end{array}$ \\
\hline
\end{tabular}

*The total number exceeds the number of patients who reported taking pain medication because some patients reported taking more than one type of drug. 
Table 2. Descriptive Statistics for Pain and Pain-Free Patients

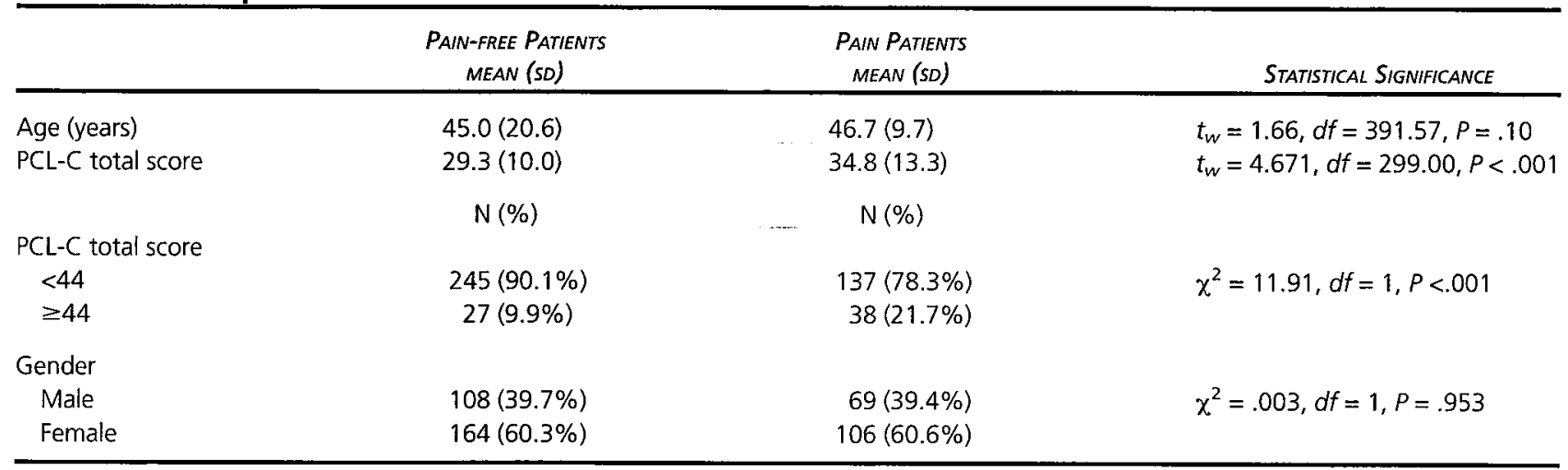

\section{Pain}

Classification of patients into a group of pain patients and a group of pain-free patients was based on pain-related questions taken from the Current Pain and Pain History Questionnaire created for the purpose of this study (see Table 1). If patients answered "yes" to the question "Do you have ongoing pain problems", they were assigned to the pain group regardless of whether they were currently experiencing pain. If patients answered "no" to both "Do you have ongoing pain problems" and "Are you currently feeling pain", patients were assigned to the pain-free group. Patients who reported no ongoing pain problems but currently feeling pain $(\mathrm{N}=18)$ or omitted the question about their current pain $(\mathrm{N}=8)$ were excluded from the analysis to avoid misclassification of patients.

\section{Procedure}

The project was reviewed and approved by the Research Ethics Board at the University Health Network (Toronto General Hospital) and the Human Participants Review Committee at York University. Participants were approached by a research team member during the preadmission visit 7 to 10 days prior to surgery. Patients met inclusion criteria if: (1) they were scheduled to undergo major surgery at the Toronto General Hospital; (2) they were to receive intravenous or epidural patient-controlled analgesia (PCA); (3) they were between 18 and 60 years of age; and (4) they were proficient in both written and spoken English. Patients were excluded if they were scheduled to receive other regional anaesthetic techniques during or after surgery. Once written consent was obtained, patients completed a preadmission selfreport questionnaire package that included measures of PTSD symptoms and pain.

\section{Data Analyses}

Exploratory Factor Analysis (EFA) was favored over Confirmatory Factor Analysis (CFA) to examine group differences in PTSD-symptom structure between pain-free and pain patients. The latter aims at confirming the validity of a theoretical mode ${ }^{20}$ whereas the former tries to uncover the underlying structure. We selected EFA because very little is known about the structure of PTSD symptoms in patients with and without chronic pain. EFA permits evaluation of symptom item performance, enabling us to assess whether there is a different latent dimensional structure in PTSD symptoms between pain and pain-free patients.

Analyses followed current recommendations for EFA on ordinal data. ${ }^{25,26,35,44}$ First, Velicer's MAP test and parallel analysis (PA) using $O^{\prime}$ Connor's syntax ${ }^{35}$ with Principal Component Analysis (PCA) on polychoric correlation matrix were used to determine the number of components to retain. Second, Principal Axis Factoring (PAF) on polychoric correlation matrices and Promax rotation were used to extract factor loadings and interpret the final solution. The factor solution resulting from the EFA describes the number of underlying interrelated groups of variables or factors. As such, PTSD symptoms belonging to the same factor represent an underlying construct. For example, a 2-factor solution signifies that PTSD is composed of 2 underlying constructs each comprised of a subset of PTSD symptoms. Data are presented as mean \pm SD unless otherwise specified.

\section{Results}

\section{Descriptive Statistics}

Descriptive statistics are presented in Table 2. Pearson Chi-Square test did not reveal a significant gender difference between pain and pain-free patients and Welch's t-test (adjusted for heterogeneity of variance) did not reveal a significant difference in $\mathrm{PCL}-\mathrm{C}$ total score between males $(30.7 \pm 11.4)$ and females $(32 \pm 11.9)$. irrespective of the pain categorization $\left(t_{w}=-1.09\right.$, $\mathrm{df}=388.18, P=.276)$. Welch's t-test did not reveal an age difference between pain and pain-free patients. Welch's t-test showed a significant difference in total score on the PCL-C between pain and pain-free patients. Pearson Chi-Square test revealed a significant difference in the number of patients with a score of 44 or above on the PCL-C between pain and pain-free patients.

\section{Exploratory Factor Analysis}

Statistical procedures used to perform EFA as well as decision criteria used to determine the optimal PTSD model for pain and pain-free patients are presented in Table 3. 
Table 3. Details of Exploratory Factor Analyses and Criteria Used to Determine the Final PTSD Symptom Model for Pain and Pain-Free Patients

Using MAP TEst AND PA to DeCIDE the NUMBER of FACTORS to RetaIN

PAIN PATIENTS

PAIN-FREE PATIENTS

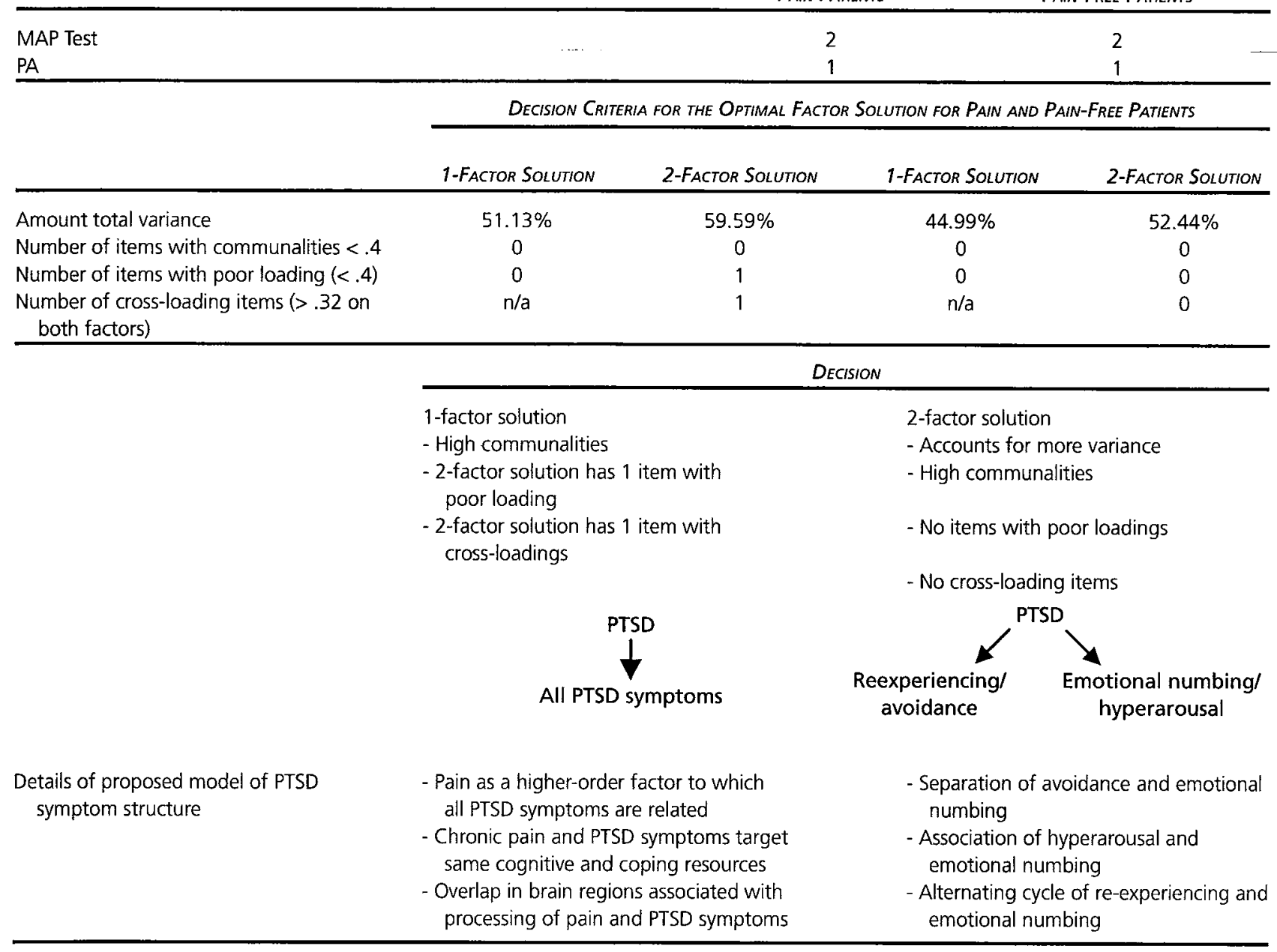

\section{Pain Patients}

EFA of the 17 PCL-C items using MAP test and PA with polychoric correlation matrix and PCA followed by PAF and Promax rotation was performed to determine the factor solution that best fit the data. Results are presented in Table 3. Parallel analysis using real-data eigenvalues generated with SAS yielded a 1-factor solution. Results from Velicer's MAP test using $O^{\prime}$ Connor's original and revised syntax yielded a 2-factor solution. Results of PA are presented in Fig 1.

PAF on polychoric correlation and oblique rotation (Promax) was performed to determine if a 1- or a 2-factor solution best fit the data. Each factor solution was evaluated based on significance of communalities and cross-loadings. Significance of communalities was assessed using a cut-off of .4, as communalities lower than .4 suggest the presence of an additional factor or that the item is unrelated to the other items. ${ }^{15}$ Crossloading was defined as any item with loadings greater than .32 on more than 1 factor. ${ }^{15}$ Results are shown in Tables 3 and 4. Significance of factor loadings and cross-loadings were used as criteria to select the optimal factor solution. The 1-factor solution accounted for $51.13 \%$ of the variance, had all communalities above .4 , and the factor had an eigenvalue of 9.17. The 2-factor solution accounted for $59.59 \%$ of the variance, all communalities were greater than .4 , and factors 1 and 2 had eigenvalues of 9.17 and 1.70 , respectively. Crossloading ( $\geq .32$ ) of item 8 and loadings $<.4$ on both factors for item 16 suggested the 1-factor solution was the best fit.

\section{Pain-Free Patients}

Following the same methodology used for pain patients, results from PA yielded a 1-factor solution, whereas results of the MAP test yielded a 2-factor solution (see Table 3). Results of PA are presented in Fig 2.

Table 4 shows results from the PAF. The 1-factor solution accounted for $44.99 \%$ of the variance with all factor communalities greater than .4, and an eigenvalue of 8.17. The 2-factor solution accounted for $52.44 \%$ of the variance, had eigenvalues for factors 1 and 2 of 8.17 and 1.64 respectively, communalities greater than .4 for all items, and no cross-loadings. Therefore, the 


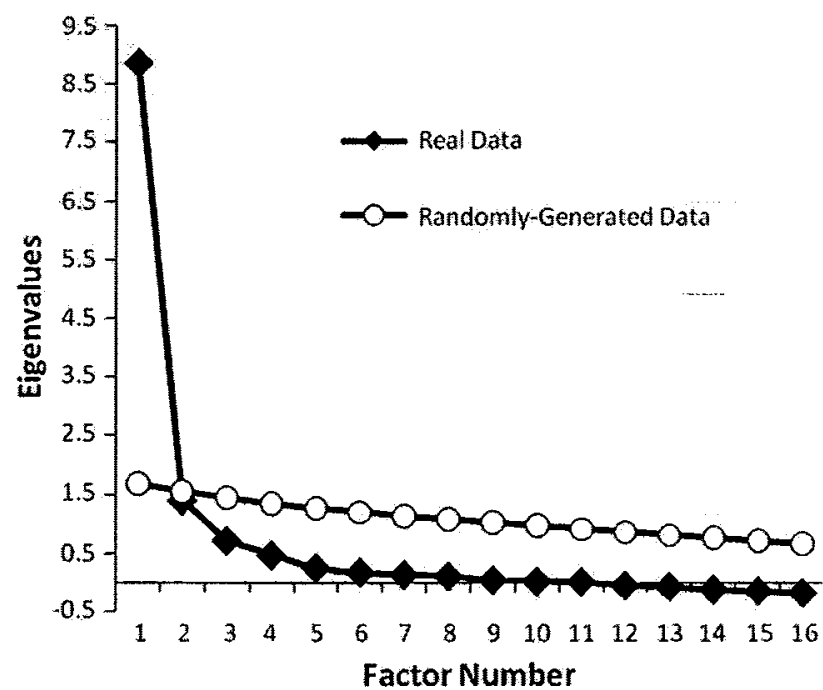

Figure 1. Results of Parallel Analysis for pain patients.

2-factor solution presented the best fit to the data. Examination of the pattern of item loadings on factors 1 and 2 indicates the presence of a re-experiencing/avoidance factor and an emotional numbing/hyperarousal factor, respectively.

\section{Discussion}

The results of the present study show that the internal factor structure of PTSD symptoms, as measured by the $\mathrm{PCL}-\mathrm{C}$, differs in pain and pain-free patients scheduled to undergo major surgery. For both groups, Velicer's MAP test indicated a 2-factor solution, whereas PA
Structure of PTSD Symptoms in Pain and Pain-Free Patients revealed a 1-factor solution. Examination of percentage of variance accounted for, communalities, and item cross-loading, suggested the best fit was a 1-factor solution for pain patients and a 2-factor solution for pain-free patients. In addition, pain patients scored significantly higher on the PCL-C total score compared to pain-free patients. Moreover, rates of PTSD symptomology in the clinical range (score of 44 or above on the PCL-C) were $21.7 \%$ in pain patients compared to $9.9 \%$ for pain-free patients. These results suggest that PTSD symptoms are more elevated among pain patients. Although it is not possible to identify patients with PTSD using a self-report measure such as the PCL-C, our data suggest that approximately $21.7 \%$ of pain patients experienced PTSD symptoms in the clinical range. This rate is similar to those reported in other studies on the comorbidity of PTSD and pain in civilian populations $(20-30 \%)$. $^{3,32}$

\section{Pain-Free Patients: A 2-Factor Solution}

Outcomes of the factor analysis in pain-free patients favored a 2-factor solution comprised of re-experiencing/avoidance and emotional numbing/hyperarousal factors. Details of the 2-factor solution are presented in Table 3. This 2-factor solution is consistent with several studies conducted on war veterans, ${ }^{16}$ peacekeepers, ${ }^{41}$ and fire and motor vehicle accident victims. ${ }^{12,31}$ The 2-factor solution is not only found in different populations (both clinical and community-based as well as military and civilian), but also with the use of different measures (eg, Composite International Diagnostic Interview, Anxiety Disorder Interview Schedule, PTSD Symptom Scale, Impact Event Scale-Revised, Clinician

Table 4. Details of 1- and 2-Factor Solutions for Pain and Pain-Free Patients

\begin{tabular}{|c|c|c|c|c|c|c|}
\hline \multirow[b]{3}{*}{ PCL-C ITEM } & \multicolumn{3}{|c|}{ PAIN PATIENTS } & \multicolumn{3}{|c|}{$P_{\text {AIN-FRE }} P_{\text {ATIENTS }}$} \\
\hline & \multirow{2}{*}{$\begin{array}{l}\text { 1-FACTOR } \\
\text { (MATRIX) }\end{array}$} & \multicolumn{2}{|c|}{ 2-FACTORS } & \multirow{2}{*}{$\begin{array}{l}\frac{1-F_{A C T O R}}{} \\
\text { (MATRIX) }\end{array}$} & \multicolumn{2}{|c|}{ 2-FACTORS } \\
\hline & & F1 & $F 2$ & & F1 & $F 2$ \\
\hline 1. Disturbing memories & .725 & .983 & -.187 & .741 & .700 & .098 \\
\hline 2. Disturbing dreams & .758 & .833 & -.007 & .594 & .610 & .027 \\
\hline 3. Feeling happening again & .811 & .800 & .082 & .763 & .951 & -.123 \\
\hline 4. Upset with reminders & .762 & .862 & -.031 & .754 & .873 & -.058 \\
\hline 5. Physical reactions to reminders & .742 & .821 & -.013 & .676 & .773 & -.045 \\
\hline 6. Avoid thoughts of event & .808 & .676 & .199 & .675 & .708 & .017 \\
\hline 7. Avoid activities that remind of event & .694 & .578 & .173 & .722 & .680 & .097 \\
\hline 8. Trouble remembering event & .741 & .442 & .361 & .581 & .491 & .134 \\
\hline 9. Apathy & .678 & .183 & .559 & .747 & .202 & .618 \\
\hline 10. Feeling distant, cut off & .714 & .023 & .768 & .737 & .237 & .569 \\
\hline 11. Feeling emotionally numb & .764 & .056 & .790 & .745 & .318 & .492 \\
\hline 12. Feeling as if future cut short & .699 & .161 & .606 & .590 & .102 & .548 \\
\hline 13. Trouble falling asleep & .625 & -.028 & .722 & .454 & -.111 & .622 \\
\hline 14. Irritable or angry outbursts & .654 & -.067 & .796 & .684 & -.051 & .822 \\
\hline 15. Difficulty concentrating & .696 & -.129 & .913 & .630 & -.122 & .836 \\
\hline 16. Watchful or on guard & .535 & .379 & .200 & .511 & .050 & .514 \\
\hline 17. Feeling jumpy, easily startled & .699 & .173 & .593 & .696 & .044 & .731 \\
\hline Total Variance $(\%)$ & 51.13 & 51.64 & 7.95 & 44.99 & 45.43 & 7.00 \\
\hline
\end{tabular}




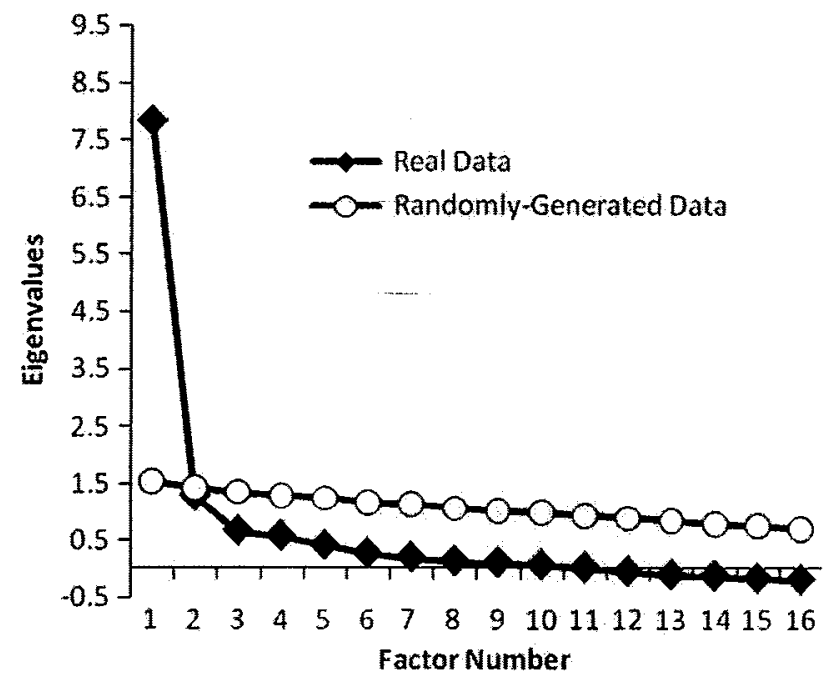

Figure 2. Results of Parallel Analysis for pain-free patients.

Administered PTSD Scale, and PCL-C), ${ }^{12,16,31,41}$ and statistical procedures (EFA vs CFA, PCA vs PAF, PA vs scree-plot and eigenvalues-greater-than-1-rule). ${ }^{12,16,31,41}$ This consistency across measures, populations, and statistical methods strongly suggests that the 2-factor solution is an inherent characteristic of PTSD-symptom expression. The separation of emotional numbing and avoidance is also consistent with the vast majority of studies that supported a 2- or 4-factor solution.

The categorization of emotional numbing with hyperarousal is consistent with Litz et al's $\mathrm{s}^{30}$ theory that chronic hyperarousal results in emotional numbing through emotional depletion. Prolonged hyperarousal in traumatized individuals is associated with a depletion of biological, cognitive, and emotional resources. ${ }^{6,21,29}$ Emotional numbing is proposed to be the experiential expression of this depletion of resources. The 2-factor solution is also congruent with the finding that PTSD is characterised by an alternating cycle of re-experiencing and emotional numbing symptoms. ${ }^{28,43}$ This alternating process suggests that re-experiencing and emotional numbing comprise 2 different latent constructs.

\section{Pain Patients: A 1-Factor Solution}

The 1-factor solution found in pain patients contrasts with the results obtained in pain-free patients as well as with samples of patients undifferentiated based on the presence or absence of pain problems. Details of the 1-factor solution model are presented in Table 3. Among studies that have evaluated, but did not find evidence for, a 1-factor solution, ${ }^{16,42,48}$ chronic pain was not assessed. Although Asmundson et al ${ }^{5}$ found differences in factor loadings between chronic-pain and pain-free patients, their results supported a 2- and a 4-factor solution in both groups. In the 4-factor intercorrelated model, items of hyperarousal (items 14 and 15) showed cross-loadings on the emotional numbing factor in the pain group whereas 1 hyperarousal item (item 16) cross-loaded on the re-experiencing factor for the pain-free group. In the hierarchical 2-factor model, items 2 (re-experiencing) and 15 (hyperarousal) cross-loaded on both re-experiencing/avoidance and emotional numbing/hyperarousal factors in the pain group. In the study by Asmundson et al, ${ }^{5}$ item 16 (hyperarousal) cross-loaded on both factors in the pain-free group. The significant cross-loadings of factors found in both of their solutions suggest that a 1-factor solution might also have provided a good fit of the data. It is difficult to compare their results to results obtained here as they did not test a 1 -factor solution.

Several mechanisms could explain the single-factor structure obtained in pain patients. In contrast to painfree patients, in whom symptoms of re-experiencing and avoidance alternate with symptoms of emotional numbing and hyperarousal, we suggest than in pain patients, the pain will trigger the appearance or intensification of symptoms of re-experiencing/avoidance and emotional numbing/hyperarousal. This influence of pain could be due to both the physiological consequences associated with pain but also psychological impact of pain (eg, fear of pain). This conceptualization suggests that pain may serve as a higher-order factor to which each PTSD symptom cluster is related. The concept of pain as a higher-order factor is supported by evidence from cognitive treatments. Research has shown that interventions aimed at reducing psychological difficulties associated with traumatic experiences are also effective in treating chronic pain symptoms. ${ }^{23}$

Moreover, research has shown that each PTSD symptom cluster is associated with symptoms of chronic pain. First, symptoms of re-experiencing are distinctively associated with pain disability and pain severity. ${ }^{4,7}$ Second, symptoms of avoidance are at the core of the fear-avoidance model of chronic pain. ${ }^{45}$ Third, physiological arousal (which includes some PTSD symptoms of hyperarousal) is associated with increased pain intensity. ${ }^{34}$ Fourth, research has shown that postoperative concurrent levels of emotional numbing predict pain disability at 6 months and 1 year after surgery. ${ }^{14,27}$ Together, these findings raise the possibility that each of the 4 PTSD symptom clusters is interpreted by patients with PTSD as part of their pain experience.

Alternatively, pain patients might lack cognitive and coping resources to deal with both pain and PTSD experiences. Empirical evidence supports an association between chronic pain and cognitive resources. Studies have shown that chronic pain patients exhibit deficits in cognitive-processing ability, ${ }^{2,24,36}$ and that cognitive tasks can serve as distracters resulting in decreased intensity of perceived pain through an attentional-allocation mechanism. ${ }^{17}$ In addition, cognitive approaches to PTSD conceptualize this anxiety disorder as involving memory processes that generate a sense of current threat. ${ }^{18}$ As such, chronic pain might impair cognitive resources and, thereby, intensify the occurrence of PTSD symptoms.

It is also possible that common brain regions involved in pain and PTSD contribute to the interpretation of PTSD symptoms as part of the pain experience. Studies have shown that pain-related activation and anticipation of pain are detected in the insula. ${ }^{37}$ Research has also demonstrated a positive association between 
activation of the insula and severity of PTSD symptoms. ${ }^{13}$ It is possible that, by activating brain regions also associated with pain, PTSD symptoms are interpreted as part of the pain experience.

\section{Limitations and Future Directions}

One limitation of this study is the unknown nature of the traumatic experiences to which the patients were responding when completing the PCL-C. The PCL-C does not require the patient to describe his or her traumatic experience, and a traumatic event questionnaire was not used to supplement administration of the PCL-C.

In addition, EFA is meant to be exploratory in nature and not inferential. Even with large sample sizes such as that used in this study, EFA can generate error rates above the set alpha level. ${ }^{15} \mathrm{It}$ is also dependent on the choices made by researchers in terms of methods used for the various steps of the analysis. ${ }^{19}$ Results from EFA should be understood as exploratory and serve as the basis for further studies. Future studies should also make use of other methodologies to further investigate the structure of PTSD symptoms in patients with pain. As mentioned by Asmundson et al, ${ }^{4}$ other lines of research include: (1) the relationship of PTSD symptoms to prog-

\section{References}

1. APA: Diagnostic and Statistical Manual of Mental Disorders DSM-IV-TR, 4th Edition (Text Revision). Arlington, VA, American Psychiatric Publishing, 2000

2. Apkarian AV, Sosa $Y$, Krauss BR, Thomas PS Fredrickson BE, Levy RE, Harden RN, Chialvo DR: Chronic pain patients are impaired on an emotional decision-making task. Pain 108:129-136, 2004

3. Asmundson GJG, Coons MJ, Taylor S, Katz J: PTSD and the Experience of Pain: Research and Clinical Implications of Shared Vulnerability and Mutual Maintenance Models. The Canadian Journal of Psychiatry/La Revue canadienne de psychiatrie 47:930-937, 2002

4. Asmundson GJG, Stapleton JA, Taylor S: Avoidance and numbing are distinct PTSD symptom clusters. Journal of Traumatic Stress 17:467-475, 2004

5. Asmundson GJG, Wright KD, McCreary DR, Pedlar D: Posttraumatic stress disorder symptoms in United Nations peacekeepers: An examination of factor structure in peacekeepers with and without chronic pain. Cognitive Behaviour Therapy 32:26-37, 2003

6. Barlow DH: Anxiety and its disorders, 2nd edition. New York, NY, The Guilford Press, 2004

7. Beckham JC, Crawford AL, Feldman ME, Kirby $A C$, Hertzberg MA, Davidson JRT, Morre SD: Chronic posttraumatic stress disorder and chronic pain in Vietnam combat veterans. Journal of Psychosomatic Research 43:379-389, 1997

8. Blanchard EB, Jones-Alexander J, Buckley TC, Forneris CA: Psychometric properties of the PTSD Checklist (PCL). Behaviour Research and Therapy 34:669-673, 1996

9. Breslau N, Chase GA, Anthony JC: The uniqueness of the DSM definition of Post-traumatic Stress Disorder: Implications for Research. Psychological Medicine 32:573-576, 2002
Structure of PTSD Symptoms in Pain and Pain-Free Patients nosis; (2) treatment effects on individual PTSD symptoms; and (3) the correlates of PTSD symptoms.

Nonetheless, results from this study are important for understanding the relationship between PTSD and pain. If the clinical expression of PTSD symptoms differs between patients with and without pain, it is possible that different etiological and maintenance mechanisms are at work. As such, the results of the present study have implications for future research and clinical practice with patients presenting with PTSD and PTSD symptoms. Researchers should measure and control for the presence and intensity of pain when examining PTSD symptom expression. From a clinical point of view, these findings suggest that pain and PTSD symptoms are closely interrelated. Both conditions should be assessed when a patient presents with one or the other, and both should be the focus of common treatment goals as opposed to being seen as expressions of 2 separate conditions.

\section{Acknowledgments}

We thank Eileen Halket and Maria Dzyuba for data collection. Research conducted at the Toronto General Hospital, Toronto, Canada.

10. Breslau N, Reboussin BA, Anthony JC, Storr CL: The structure of Posttraumatic Stress Disorder: Latent class analysis in 2 community samples. Archives of General Psychiatry 62: 1343-1351, 2005

11. Broman-Fulks JJ, Ruggiero KJ, Green BA, Kilpatrick DG, Danielson CK, Resnick H, Saunders BE: Taxometric investigation of PTSD: data from two nationally representative samples. Behavior Therapy 37:364-380, 2006

12. Buckley TC, Blanchard EB, Hickling EJ: A confirmatory factor analysis of posttraumatic stress symptoms. Behaviour Research and Therapy 36:1091-1099, 1998

13. Carrion VG, Garrett A, Menon V, Weems CF, Reiss AL: Posttraumatic stress symptoms and brain function during a response-inhibition task: An fMRI study in youth. Depression \& Anxiety 25:514-526, 2008

14. Clapp JD, Beck JG, Palyo SA, DeMond MG: An examination of the synergy of pain and PTSD on quality of life: Additive or multiplicative effects? Pain 138:301-309, 2008

15. Costello $A B$, Osborne JW: Best practices in exploratory factor analysis: Four recommendations for getting the most from your analysis. Practical Assessment, Research, \& Evaluation 10: Available at: http://pareonline.net/pdf/ v10n17.pdf 2005

16. Creamer M, Bell R, Failla S: Psychometric properties of the Impact of Event Scale-Revisited. Behaviour Research and Therapy 41:1489-1496, 2003

17. Eccleston $\mathrm{C}$ : The attentional control of pain: methodological and theoretical concerns. Pain 63:3-10, 1995

18. Ehlers A, Clark DM: A cognitive model of posttraumatic stress disorder. Behaviour Research and Therapy 38:319-345, 2000

19. Fabrigar LR, Wegener DT, MacCallum RC, Strahan EJ: Evaluating the use of exploratory factor analysis in psychological research. Psychological Methods 4:272-299, 1999

20. Floyd FL, Widaman KF: Factor analysis in the development and refinement of clinical assessment instruments. Psychological Assessment 7:286-299, 1995 
21. Foa EB, Zinbarg R, Rothbaum BO: Uncontrollability and unpredictability in Post-Traumatic Stress Disorder: An animal model. Psychological Bulletin 112:218-238, 1992

22. Forbes D, Creamer M, Biddle D: The validity of the PTSD Checklist as a measure of symptomatic change in combat-related PTSD. Behaviour Research and Therapy 39:977-986, 2001

23. Geisser ME, Colwell MO: Chronic back pain: Conservative approaches, in Block AR, Fernandez E, Kremer EF (eds): Handbook of Pain Syndromes: Biopsychosocial Perspectives, 1st Edition. Kahwah, NJ, Lawrence Erlbaum Associates, 1999, pp 169-190

24. Harman K, Ruyak P: Working through the pain: a controlled study of the impact of persistent pain on performing a computer task. Clinical Journal of Pain 21:216-222, 2005

25. Hayton JC, Allen DG, Scarpello V: Factor retention decisions in exploratory factor analysis: A tutorial on parallel analysis. Organizational Research Methods 7:191-205, 2004

26. Horn JL: A rationale and test for the number of factors in factor analysis. Psychometrika 30:179-185, 1965

27. Katz J, Asmundson GJG, McRae K, Halket E: Emotional numbing and pain intensity predict the development of pain disability up to one year after lateral thoracotomy. European Journal of Pain [serial online]. e2008. Accessed 15 October 2008

28. Krystal H: An information processing view of objectrelations. Psychoanalytic Inquiry 10:221,251, 1990

29. Litz B: Emotional numbing in combat-related post-traumatic stress disorder: A critical review and reformulation. Clinical Psychology Review 12:417-432, 1992

30. Litz BT, Schlenger WE, Weathers FW, Caddell JM, Fairbank JA, LaVange LM: Predictors of emotional numbing in posttraumatic stress disorder. Journal of Traumatic Stress 10:607-618, 1997

31. Maes M, Delmeire L, Schotte C, Janca A, Creten T, Mylle J, Struyf A, Pison G, Rousseeuw PJ: The two-factorial symptom structure of post-traumatic stress disorder: depression-avoidance and arousal-anxiety. Psychiatry Research 81:195-210, 1998

32. McWilliams LA, Cox B, Asmundson GJG: Symptoms structure of posttraumatic stress disorder in a nationality representative sample. Journal of Anxiety Disorders 19:626-641, 2005

33. McWilliams LA, Cox BJ, Enns MW: Mood and anxiety disorders associated with chronic pain: An examination in a nationally representative sample. Pain 106:127-133, 2003

34. Norton PJ, Asmundson GJG: Amending the fear-avoidance model of chronic pain: What is the role of physiological arousal? The Behavior Therapist 34:17-30, 2003

35. O'Connor B: SPSS and SAS programs for determining the number of components using parallel analysis and Velicer's
MAP test. Behavior Research Methods, Instruments, and Computers 32:396-402, 2000

36. Park DC, Glass JM, Minear M, Crofford L: Cognitive function in fibromyalgia patients. Arthritis Rheumatology $44: 2125-2133,2001$

37. Ploghaus A, Tracey I, Gati JS, Clare S, Menon RS, Matthews PM, Rawlins JN: Dissociation pain from its anticipation in the human brain. Science 284:1979-1981, 1999

38. Reiss S, McNally RJ: Expectancy model of fear, in Reiss S, Bootzin RR (eds): Theoretical issues in behavior therapy, 1st Edition. San Diego, CA, Academic Press, 1985, pp 107-121

39. Ruggiero KJ, DelBen K, Scotti JR, Rabalais AF: Psychometric properties of the PTSD Checklist-Civilian version. Journal of Traumatic Stress 16:495-502, 2003

40. Sharp TJ, Harvey AG: Chronic pain and posttraumatic stress disorder: mutual maintenance? Clinical Psychology Review 21:857-877, 2001

41. Taylor S, Kuch K, Koch WJ, Crockett DJ, Passey G: The structure of posttraumatic stress symptoms. Journal of Abnormal Psychology 107:154-160, 1998

42. Tull MT, Roemer L: Alternative explanations of emotional numbing of posttraumatic stress disorder: an examination of hyperarousal and experiential avoidance. Journal of Psychopathology and Behavioral Assessment 25:147-154, 2003

43. van der Kolk BA: Psychological Trauma, 1st Edition. Washington, DC, American Psychiatric Press, 1987

44. Velicer WF, Eaton CA, Fava JL: Construct explication through factor component analysis: A review and evaluation of alternative procedures for determining the number of factors or components, in Goffin RD, Helmes E (eds): Problems and Solutions in Human Assessment: Honoring Douglas N. Jackson at Seventy, 1st Edition. Boston, MA, Kluwer Academic Publishers, 2000, pp 41-72

45. Vlaeyen JWS, Linton SJ: Fear-avoidance and its consequences in chronic musculoskeletal pain: A state of the art. Pain 85:317-332, 2000

46. Weathers FW, Huska JA, Keane TM: PCL-C for DSM-IV, Boston. MA, National Center for PTSD - Behavioral Science Division, 1991

47. Weathers FW, Litz BT, Herman DS, Huska JA, Keane TM: The PTSD Checklist (PCL): Reliability, validity, and diagnostic utility. San Antonio, TX, International Society for Traumatic Stress Studies, 1993

48. Weiss DS, Marmar CR: The Impact of Event Scale-Revised, in Wilson JP, Keae TM (eds): Assessing Psychological Trauma and PTSD: A Handbook for Practitioners, 1st Edition. New York, NY, Guilford Press, 1997, pp 399-411 